\title{
Islanding detection in a distribution network with distributed generators using signal processing techniques
}

\author{
Seong-Cheol Kim ${ }^{1}$, Papia Ray $^{2}$, Surender Reddy Salkuti ${ }^{3}$ \\ ${ }^{1,3}$ Department of Railroad and Electrical Engineering, Woosong University, Daejeon, Republic of Korea. \\ ${ }^{2}$ Department of Electrical Engineering, Veer Surendra Sai University of Technology, Burla, India.
}

\begin{tabular}{l} 
Article Info \\
\hline Article history: \\
Received Apr 14, 2020 \\
Revised May 1, 2020 \\
Accepted Jun 17, 2020 \\
\hline
\end{tabular}

Keywords:

Artificial neural networks Distributed generation Feature selection Islanding detection Signal processing techniques Stochastic optimization

\section{Corresponding Author:}

Surender Reddy Salkuti, Department of Railroad and Electrical Engineering,

Woosong University, 17-2, Jayang-Dong, Dong-Gu, Daejeon - 34606, Republic of Korea.

Email: surender@wsu.ac.kr

\begin{abstract}
This paper proposes quick \& accurate islanding detection technique for a distribution system with distributed generators (DGs). Here two schemes of islanding detection based on signal processing is proposed of which one is based on discrete wavelet transform (DWT) with artificial neural network (ANN), and another one is based on S-transform with ANN. The negative sequence current/voltage signals are retrieved at targeted DG location which are used for islanding detection in the distribution system. Here, the wavelet and S-transforms are used for fault location and classification applications. Further, the feature extraction is used for reducing the size of data matrix by transforming it into set of features. In this work, particle swarm optimization (PSO) based feature selection scheme is applied. Simulation results on test system indicate the efficacy of proposed islanding detection techniques.
\end{abstract}

This is an open access article under the CC BY-SA license.

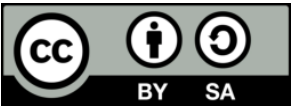

\section{INTRODUCTION}

Protection engineers face challenges in certain applications such as islanding detection in a distribution network. Island is a situation where a part of a utility grid is energized by DGs and electrically separated from rest of the network. It is very much important to detect islanding condition correctly \& quickly, otherwise risk of damage to the power system rises \& safety hazard for the personnel becomes a matter of concern. Several power systems face the issue of low frequency oscillation due heavy load condition or to system interconnection. The stability of a power system is a non-linear, dynamic phenomenon, and it depends on poorly damped low frequency oscillations. These oscillations play vital role in the analysis of stability of the system. If these oscillations are not damped sufficiently, an unstable operation may occur and it may lead to a network collapse. Therefore, it is essential to monitor the modal parameters of the low frequency oscillatory signals for dynamic system security [1].

Reference [2] presents several islanding detection techniques such as active inverter-resident techniques, passive inverter-resident techniques, communications-based techniques, and utility level techniques for distributed power generation systems. In Reference [3], an islanding scheme based on wavelet singular entropy is implemented in a microgrid with DG. A hybrid analyzing method which analyzes the daxis voltage component in 2 ways for detecting the islanding precisely is presented in [4]. A hybrid islanding detection method for microgrids (MGs) with various connection points to smart grids (SGs) is proposed in [5], and it based on probability of islanding calculated at the SG side and sent to the central control for MG. Reference [6] analyzes the sensitivity of 16 power system parameters which are used in passive methods to 
detect non-islanding and islanding events. An islanding detection method based on islanding discrimination factor is proposed in [7], and it is derived from the superimposed components of voltages. An islanding detection method based on average absolute frequency deviation value is presented in Reference [8].

An islanding detection method for MGs considering small scale synchronous generators is presented in [9]. Tuned filters connected at the DG terminals are utilized for islanding detection in MG is proposed in [10]. An islanding detection method based on modal components of voltages is discussed in [11]. An active islanding detection method for an inverter-based DG is proposed in [12]. A passive local multi-criteria based islanding detection technique with fault detection as well as islanding verification logic is proposed in [13]. Reference [14] presents an efficient approach for building decision trees-based intelligent relay. A new large performance islanding search sequence method implemented to 4 islanding detection approaches is proposed in [15]. A new passive-based anti-islanding technique for both synchronous machine \& inverter based DGs is proposed in [16].

It can be noticed from the literature survey that there is a pressing requirement for fast and accurate algorithm for islanding detection. Therefore, in this paper, two signal processing based islanding detection methods, i.e., DWTwith ANN, and S-transform with ANN are proposed. Here, PSO based feature selection (FS) algorithm is used. The suitability and effectiveness of proposed islanding detection methods has been examined on distribution network with DGs.

\section{PROPOSED SIGNAL PROCESSING TECHNIQUES FOR ISLANDING DETECTION}

In this paper, DWT and S-transforms are applied for detecting the islanding in the distribution network.

\subsection{Islanding detection using discrete wavelet transform (DWT) with ANN}

Wavelet transform (WT) is an adaptive signal processing technique for non-stationary signals and it extractsinformation from the data series. Choice of desired mother wavelet is vital for good performance, and Daubechies is considered as the appropriate one for analyzing the transient event [17]. Here, WT is applied for islanding detection. Signal is collected from the relaying end of distribution line is decomposed into 8 level by WT, and it is depicted in Figure 1. Sampling frequency is considered as $30 \mathrm{kHz}$, therefore, 8 level decomposition can be performed [18]. For the accuracy of the model, sampling frequency of $30 \mathrm{kHz}$ is required. Decomposition process depends on sampling frequency (Fs) and number of samples

Decomposition process with digital filtering approach is depicted in Fig.1. In this figure, X[n] is signal, $\mathrm{g}[\mathrm{n}]$ is high pass filter, and $\mathrm{h}[\mathrm{n}]$ is low pass filter [19-20]. ' $\mathrm{d} 1$ ' and ' $\mathrm{a} 1$ ' are $1^{\text {st }}$ level detail and approximation coefficients, respectively.

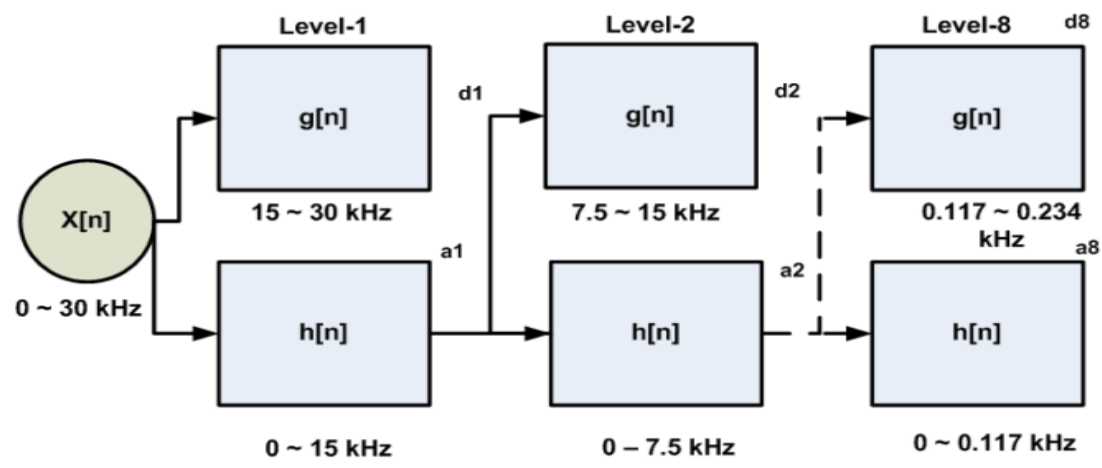

Figure 1. Digital filtering technique of wavelet transform (WT).

ANN is a computational model that simulates the structural and functional aspects of biological neural network [21]. In this work, a multilayer feed-forward neural network (FFNN) with back propagation training algorithm is applied. Flow chart of islanding detection technique in a distribution network using WT and ANN is depicted in Figure 2. At the targeted distribution generation (DG) location, the negative sequence current/voltage signals are retrieved. These signals are decomposed using DWT [22]. The obtained statistical features from the signals are reconstructed from detailed coefficients. Feature set with best predictive power is chosen by using PSO algorithm. Thereafter, the train \& test data is generated from wide variation of 
loading condition and it is normalized [23]. ANN is trained with the selected features as input. Then, the testing is performed with the trained neural network.

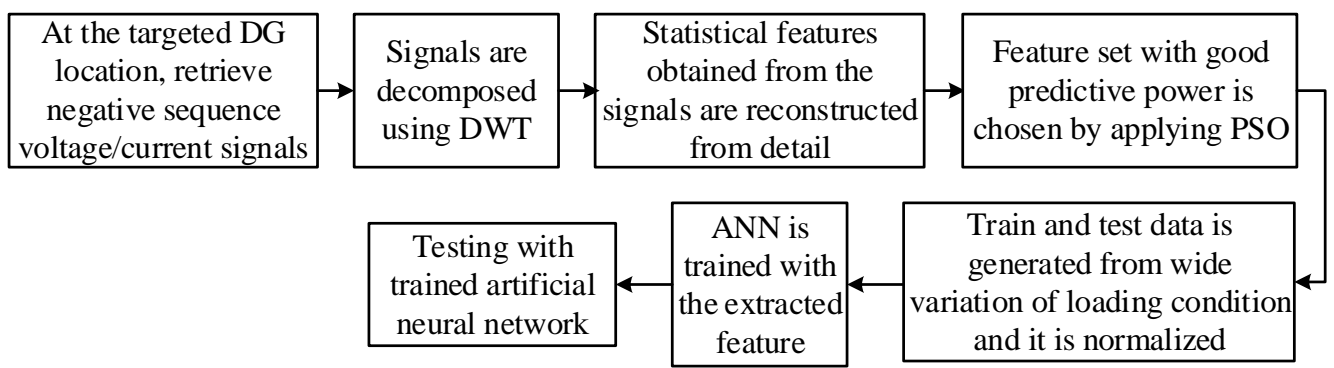

Figure 2. Islanding detection technique using DWT and ANN.

\subsection{Islanding detection using $S$-Transform with ANN}

S-transform represents the time-frequency relationship with instantaneous values of frequency, phase and amplitude [24]. It gives the absolutely referenced phase information \& frequency invariant amplitude response \& provides better signal clarity for transient signal. Generates a contour which is simple to visualize, whereas WT requires standard multi-resolution analysis. However, it requires higher complex computation [25]. S-transform confines the real \& imaginary components, phase as well as amplitude spectrums independently. It is termed as absolutely referenced phase information. S-transform is used for several applications such as fault classification, location and modal analysis of signal.

Figure 3 depicts the flow chart of proposed islanding detection scheme using S-transform \& ANN. Negative sequence voltage/current signals are acquired at the targeted DG location. S-transform is applied to these signals, and energy is determined [26-27]. The cumulative sum (CUMSUM) of energy signal is checked for the convergence condition, and this CUMSUM is used for islanding detection.

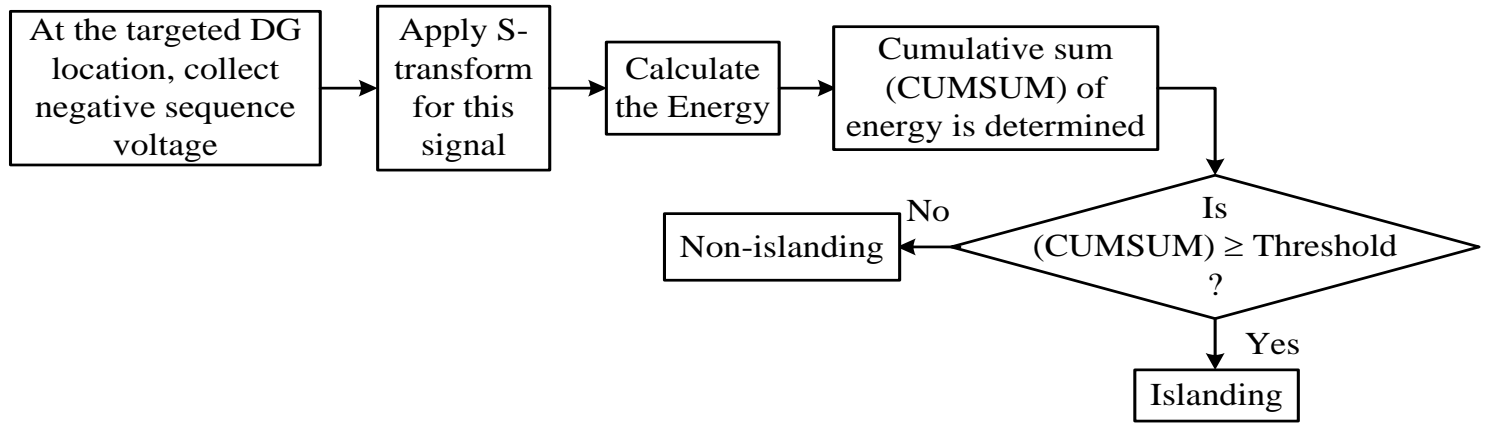

Figure 3. Islanding detection technique using S-transform and ANN.

\subsection{Feature extraction}

It is used for reducing data matrix size by transforming into features. From decomposed coefficients of DWT, six statistical features are extracted. For WT, the number of reconstructed coefficients are 8 (i.e., d1-d8) and the total feature matrix is 96 (i.e., $8^{\text {th }}$ decomposition level $\times 2$ nos of signals $\times 6$ nos of features). Total feature set for each signal for S-transforms is 18 features [28]. In S-transform, 3 parameters, i.e., frequency, phase and amplitude are considered.

The transient energy signal has large value as compared to normal signal. Standard deviation of an undistorted signal is equal to one, however, for transient signal, this value deviates from one. During the islanding event, the signal mean becomes non-zero, whereas its value is zero for undistorted signal [29-30]. For an undistorted signal, the value of kurtosis is 3 , whereas its value is greater than 3 for a transient signal. For an undistorted signal, the value of skewness is zero \& non-zero for distorted case. The value of entropy is large value for transient signal, and it is less for an undistorted signal. 


\section{FEATURE SELECTION}

Feature selection (FS) is selecting small sets of features which determine's target properly. It reduces the complexity of prediction \& learning technique \& makes prediction accuracy to rise. In various supervised learning activities, most of the features shows redundancy [31]. Therefore, FS is a significant approach towards learning of large multi-featured data matrix.

\subsection{Feature selection using PSO algorithm}

PSO is stochastic optimization approach motivated by the behavior of bird flocking or fish schooling. In PSO, the potential solution is called particles, which interacts among themselves to find global optimal solution. In every iteration, each particle has its own position \& velocity, and is updated by two best values called pbest\&gbest. For further details of PSO algorithm, the reader may refer reference [32]. The flow chart of PSO based FS is depicted in Fig. 4.

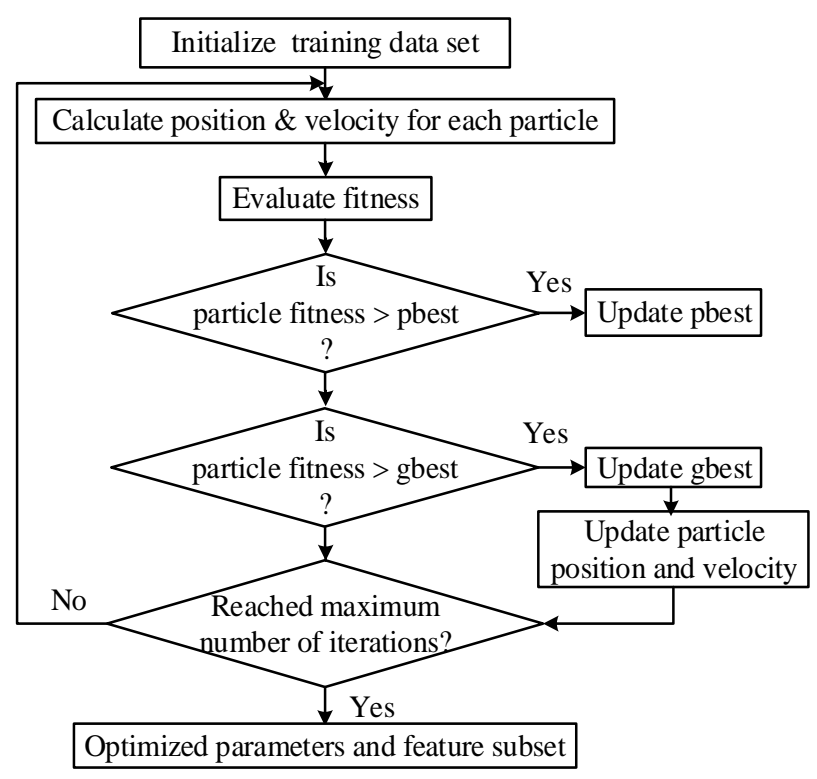

Figure 4: Flow chart of PSO based feature selection.

\subsection{Parameter setting for generating train \& test data matrix}

The train \& test data matrix is normalized between [0,1]. For each signal, 48 features ( 8 level decomposition $\times 6$ features) for DWT, and 18 features ( 3 modal parameters $\times 6$ features) for S-transforms are considered. Optimal features are obtained from feature selection method, and they are 8 for DWT and 4 for S-transform. In this paper, two types of training data sets are considered. The first data set is formed by the combination of 7 resistances $(0 \Omega, 1 \Omega, 5 \Omega, 10 \Omega, 25 \Omega, 35 \Omega, 45 \Omega)$ and 6 inception angles $\left(10^{\circ}, 20^{\circ}, 30^{\circ}\right.$, $40^{\circ}, 50^{\circ}, 85^{\circ}$ ). Here, ten forms of event are considered with 300 locations [33]. Therefore, the total of 126000 (i.e., $10 \times 300 \times 42)$ training data matrix is formed. The second data set is formed by the combination of 9 resistances $(2 \Omega, 4 \Omega, 6 \Omega, 9 \Omega, 12 \Omega, 20 \Omega, 30 \Omega, 40 \Omega, 50 \Omega)$ and 8 inception angles $\left(5^{\circ}, 11^{\circ}, 17^{\circ}, 24^{\circ}, 32^{\circ}, 45^{\circ}\right.$, $60^{\circ}, 90^{\circ}$ ). Therefore, the total of 216000 (i.e., $10 \times 300 \times 72$ ) training data set is generated. In this paper, the accuracy (in \%) can be calculated by using [34],

$$
\% \text { Accuracy }=\frac{\mid \text { Total number of samples }- \text { Misclassified } \mid}{\text { Total number of samples }} \times 100
$$

\section{SYSTEM DESCRIPTION}

The system under study for islanding detection in a distribution network is depicted in Figure 5. The grid data considered in this work has a frequency of $50 \mathrm{~Hz}$, voltage of $120 \mathrm{kV}$, zero sequence parameters: $\mathrm{R}_{0}$ is $1.728 \Omega / \mathrm{km}$ and $\mathrm{L}_{0}$ is $0.055 \mathrm{H} / \mathrm{km}$, and the positive sequence parameters: $\mathrm{R}_{1}$ is $0.576 \Omega / \mathrm{km}$ and $\mathrm{L}_{1}$ is 0.018 $\mathrm{H} / \mathrm{km}$. Distribution line data considered in this work has the line length of $30 \mathrm{~km}$, zero sequence parameters: 
$\mathrm{R}_{0}$ is $0.826 \Omega / \mathrm{km}, \mathrm{L}_{0}$ is $6.64 \mathrm{mH} / \mathrm{km}, \mathrm{C}_{0}$ is $0.1002 \mathrm{nF} / \mathrm{km}$, positive sequence parameters: $\mathrm{R}_{1}$ is $0.2306 \Omega / \mathrm{km}$, $\mathrm{L}_{1}$ is $2.1 \mathrm{mH} / \mathrm{km}$ and $\mathrm{C}_{1}$ is $0.2266 \mathrm{nF} / \mathrm{km}$. The DG parameters has generator data: wind speedis $10 \mathrm{~m} / \mathrm{s}$, number of wind turbines are 6 , nominal power is $9 \mathrm{MW}$ (i.e., $6 \times 1.5 \mathrm{MW}$ ), voltage is $400 \mathrm{~V}$, frequency is 50 $\mathrm{Hz}$; DC bus voltage regulator gain has $k_{p}$ is $8, k_{i}$ is 400 ; grid-side converter current regulator gain has $k_{p}$ is $0.83, k_{i}$ is 5 ; speed regulator gain has $k_{p}$ is $3, k_{i}$ is 0.6 ; rotor side converter current regulator gain has $k_{p}$ is $0.6, k_{i}$ is 8 ; reactive power \& voltage regulator gain are $0.05,20$; pitch controller gain $k_{p}$ is 150 ; converter data has nominal DC bus voltage has $1150 \mathrm{~V}$ and DC bus capacitor is $10000 \mu \mathrm{F}$.

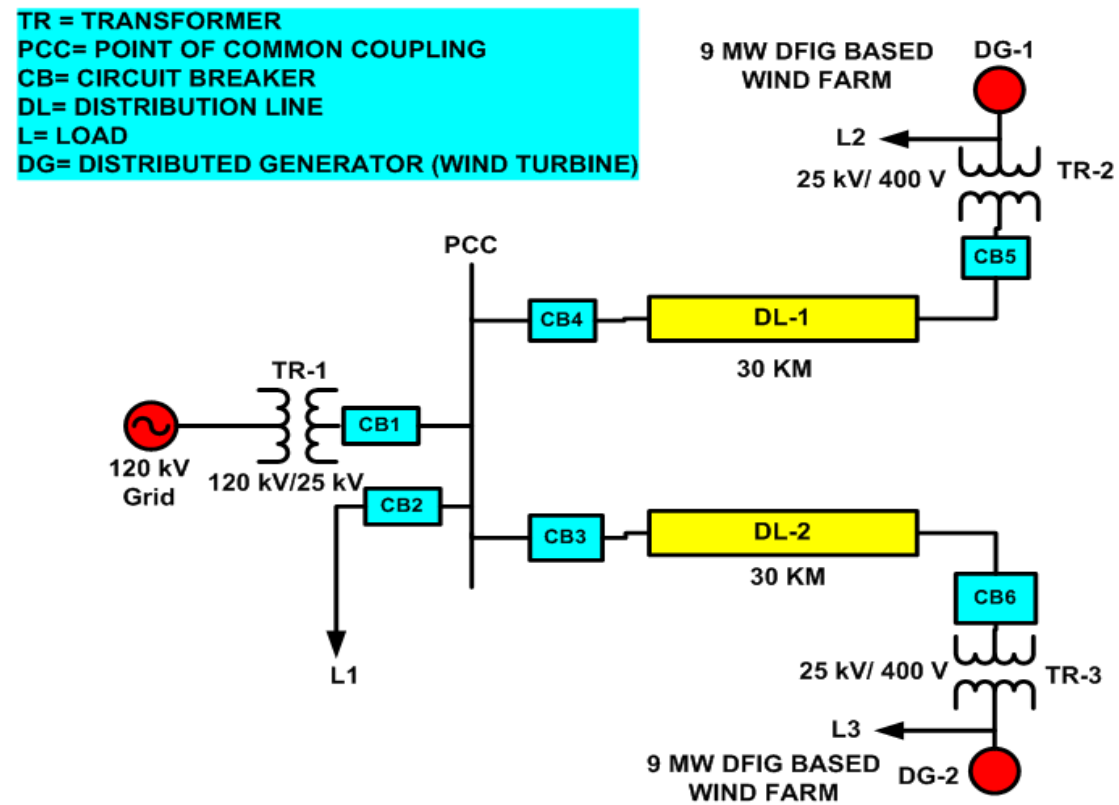

Figure 5: System under study for islanding detection.

From figure 5, it can be observed that the system under study has two $9 \mathrm{MW}$ wind farms driven by wind turbine. Each $9 \mathrm{MW}$ wind farm consists of six wind turbines of $1.5 \mathrm{MW}$ capacity connected to $120 \mathrm{kV}$ grid through $25 \mathrm{kV}, 30 \mathrm{~km}$ feeder. The sampling frequency considered is $200 \mathrm{kHz} \&$ system frequency is 50 Hz. Therefore, there is 4000 samples/cycle. Load demands are varied at DG end as well as at point of common coupling. Current samples are retrieved at DG-1 and DG-2 ends. In this work, the wind speed is considered as $10 \mathrm{~m} / \mathrm{s}$. Here, two cycles of current signal is considered, one just before islanding and another after islanding.

\section{RESULTS AND DISCUSSION}

In this paper, 18 different combinations of loading conditions are utilized to generate train \& test data. For each signal, 48 features ( 8 level decomposition $\times 6$ features) are considered for DWT. Ten optimal features are selected from the PSO based optimal feature selection method, and they are fed to ANN for training. This trained neural network is used for testing purpose. To avoid over fitting of data, ten fold cross validation is carried out [35]-[36].70\% training data and 30\% testing data will be selected randomly for the test set. Because of this, some observations may not be selected in the test set, whereas others may be selected more than once. This results in test set overlapping [37]. To overcome this situation, cross-validation is performed. In this paper, the cross validation is performed, and checked that for all the test cases error is within the limited range. Also, the proposed method in the paper is more robust than cross-validation, because in cross-validation the operating condition is already been seen by the neural network, whereas in the proposed technique, operating condition for test data is altered from trained one [38]. As mentioned earlier, in this work, two islanding detection approaches are used, and they are

- Method 1: Islanding detection using DWT with ANN.

- Method 2: Islanding detection using S-Transform with ANN. 


\subsection{Islanding detection by using method 1}

As mentioned earlier, in this method, DWT with ANN is used for islanding detection in distribution network. Table 1 presents proposed methods accuracy for islanding \& non-islanding conditions.

Table 1. Accuracy of proposed approaches for islanding \& non-islanding conditions

\begin{tabular}{ccccccccc}
\hline Condition & \multicolumn{2}{c}{ No. of samples } & \multicolumn{2}{c}{ Correct identification } & \multicolumn{2}{c}{ Mis-identification } & \multicolumn{2}{c}{ Accuracy (\%) } \\
& Method 1 & Method 2 & Method 1 & Method 2 & Method 1 & Method 2 & Method 1 & Method 2 \\
\hline Islanding & 18 & 18 & 18 & 17 & 0 & 1 & 100 & 94.4 \\
Non-islanding & 54 & 54 & 54 & 49 & 0 & 5 & 100 & 91 \\
\hline
\end{tabular}

The obtained output after using discrete wavelet transform (DWT) is fed to an ANN, and it is depicted in Figure 6.

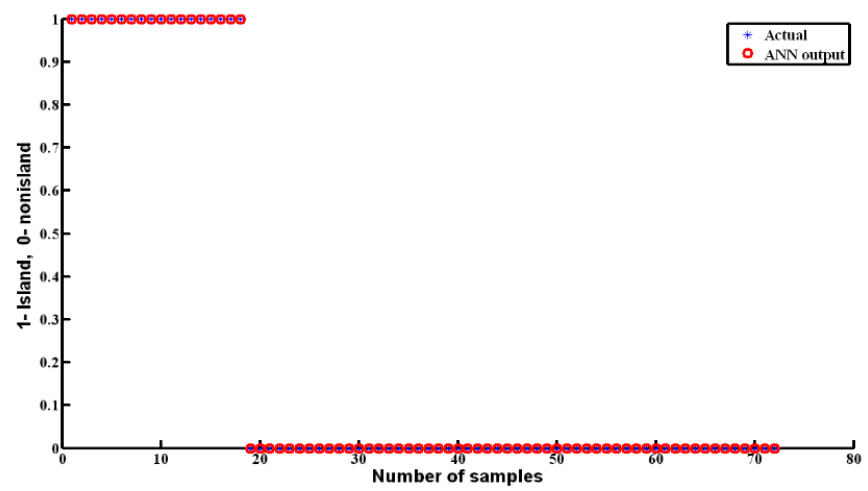

Figure 6. Islanding detection by using DWT and ANN.

Figure 6 shows ' 0 ' for fault free condition in the system, i.e., under normal operating conditions, and it shows ' 1 ' when the fault occurs under islanding condition.

\subsection{Islanding detection by using method 2}

Figure 7 depicts the plot for retrieved signal samples taken at the standard frequency of $50 \mathrm{~Hz}$, and the fault is occurred after 4000 samples.

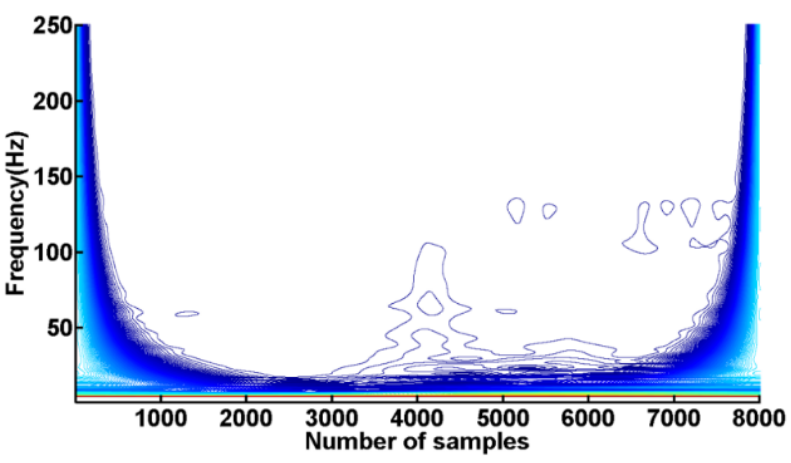

Figure 7. Islanding detection using S-transform.

From figure 7, it can be observed that after 4000 samples, there is the detection of islanding condition, and hence there is a sudden surge in the system frequency. 


\section{CONCLUSIONS}

This paper proposes an approach for detecting islanding in distribution system. Two islanding detection techniques are proposed in this paper based on DWTwith ANN, and S-transform with ANN. From the simulation results on considered system for islanding detection in a distribution network shows that the DWT in combination with ANN gave 100\% accuracy, and it is robust and more accurate than the other techniques presented in the literature. In this paper, feature selection is proposed by using PSO algorithm. Feature selection makes proposed approach more superior than other methods reported in the literature. Extending the present work to meet the problem caused due to the sudden change in load which may create false alarm in the islanding detection process is a future research scope.

\section{ACKNOWLEDGEMENTS}

This research work has been carried out based on the support of "Woosong University's Academic Research Funding - (2019-2020)".

\section{REFERENCES}

[1] A. Pouryekta, V. K. Ramachandaramurthy, N. Mithulananthan, A. Arulampalam, "Islanding Detection and Enhancement of Microgrid Performance," IEEE Systems Journal, vol. 12, no. 4, pp. 3131-3141, Dec. 2018.

[2] I.J.B. Álvarez, E.I.O. Rivera, "Survey of Distributed Generation Islanding Detection Methods," IEEE Latin America Transactions, vol. 8, no. 5, pp. 565-570, Sept. 2010.

[3] A. Samui and S. R. Samantaray, "Wavelet Singular Entropy-Based Islanding Detection in Distributed Generation," in IEEE Transactions on Power Delivery, vol. 28, no. 1, pp. 411-418, Jan. 2013.

[4] S. Murugesan, V. Murali, S.A. Daniel, "Hybrid Analyzing Technique for Active Islanding Detection Based ondAxis Current Injection," IEEE Systems Journal, vol. 12, no. 4, pp. 3608-3617, Dec. 2018.

[5] S. D. Kermany, M. Joorabian, S. Deilami and M. A. S. Masoum, "Hybrid Islanding Detection in MicrogridWith Multiple Connection Points to Smart Grids Using Fuzzy-Neural Network," IEEE Transactions on Power Systems, vol. 32, no. 4, pp. 2640-2651, Jul. 2017.

[6] S. Raza, H. Mokhlis, H. Arof, J.A. Laghari, H. Mohamad, "A Sensitivity Analysis of Different Power System Parameters on Islanding Detection," IEEE Transactions on Sustainable Energy, vol. 7, no. 2, pp. 461-470, Apr. 2016.

[7] Y.M. Makwana, B.R. Bhalja, "Islanding detection technique based on superimposed components of voltage," IET Renewable Power Generation, vol. 11, no. 11, pp. 1371-1381, Sept. 2017.

[8] P. Gupta, R.S. Bhatia, D.K. Jain, "Average Absolute Frequency Deviation Value Based Active Islanding Detection Technique," IEEE Transactions on Smart Grid, vol. 6, no. 1, pp. 26-35, Jan. 2015.

[9] R. Bekhradian, M. Davarpanah, M.S. Pasand, "Novel Approach for Secure Islanding Detection in Synchronous Generator Based Microgrids," IEEE Transactions on Power Delivery, vol. 34, no. 2, pp. 457-466, Apr. 2019.

[10] R. Dhua, D. Chatterjee, S.K. Goswami, "Harmonic filter-based improved islanding detection technique for microgrid," IET Renewable Power Generation, vol. 13, no. 13, pp. 2443-2450, Oct. 2019.

[11] Y.M. Makwana, B.R. Bhalja, "Experimental Performance of an Islanding Detection Scheme Based on Modal Components," IEEE Transactions on Smart Grid, vol. 10, no. 1, pp. 1025-1035, Jan. 2019.

[12] H.H. Zeineldin, E.F. El-Saadany, M.M.A. Salama, "Islanding detection of inverter-based distributed generation," IEE Proceedings - Generation, Transmission and Distribution, vol. 153, no. 6, pp. 644-652, Nov. 2006.

[13] H. Laaksonen, "Advanced Islanding Detection Functionality for Future Electricity Distribution Networks," IEEE Transactions on Power Delivery, vol. 28, no. 4, pp. 2056-2064, Oct. 2013.

[14] Q. Cui, K.E. Arroudi, G. Joós, "Islanding Detection of Hybrid Distributed Generation Under Reduced NonDetection Zone," IEEE Transactions on Smart Grid, vol. 9, no. 5, pp. 5027-5037, Sept. 2018.

[15] E. Serban, C. Pondiche, M. Ordonez, "Islanding Detection Search Sequence for Distributed Power Generators Under AC Grid Faults," IEEE Transactions on Power Electronics, vol. 30, no. 6, pp. 3106-3121, Jun. 2015.

[16] M. Bakhshi, R. Noroozian, G.B. Gharehpetian, "Islanding detection scheme based on adaptive identifier signal estimation method", ISA Transactions, vol. 71, no. 2, pp. 328-340, Nov. 2017.

[17] P.P. Mishra, C. N. Bhende, "Islanding detection using sparse S-transform in distributed generation systems", Electrical Engineering, vol. 100, no. 4, pp. 2397-2406, Dec. 2018.

[18] M. Ahmadipour, H. Hizam, M.L. Othman, M.A. Radzi, "Islanding detection method using ridgelet probabilistic neural network in distributed generation", Neurocomputing, vol. 329, pp. 188-209, Feb. 2019.

[19] B. M. Biaz, V. H. Ferreira, M. Z. Fortes, T. T. Lopes and G. B. A. Lima, "Islanding Detection in Distributed Generation using Unsupervised Learning Techniques," IEEE Latin America Transactions, vol. 16, no. 1, pp. 118-125, Jan. 2018.

[20] G. Bayrak, E. Kabalci, "Implementation of a new remote islanding detection method for wind-solar hybrid power plants", Renewable and Sustainable Energy Reviews, vol. 58, pp. 1-15, May 2016.

[21] R. Sirjani, C.F. Okwose, "Combining two techniques to develop a novel islanding detection method for distributed generation units", Measurement, vol. 81, pp. 66-79, Mar. 2016. 
[22] B. Anudeep, P.K. Nayak, "Sequence Component-Based Improved Passive Islanding Detection Method for Distribution System with Distributed Generations", International Journal of Emerging Electric Power Systems, vol. 20, no. 2, Apr. 2019.

[23] K. Sareen, B.R. Bhalja, S. Srivastava, Y. Swarnkar, R.P. Maheshwari, "Islanding Detection Technique based on Karl Pearson's Coefficient of Correlation for Distribution Network with High Penetration of Distributed Generations", International Journal of Emerging Electric Power Systems, vol. 19, no. 3, Jun. 2018.

[24] K. Sareen, B.R. Bhalja, R.P. Maheshwari, "A Hybrid Multi-feature based Islanding Detection Technique for Grid Connected Distributed Generation", International Journal of Emerging Electric Power Systems, vol. 18, no. 1, Feb. 2017.

[25] J.R. Reddy, A. Pandian, R. Dhanasekharan, Ch.R. Reddy, B.P. Lakshmi, B.N. Devi, "Islanding detection of integrated distributed generation with advanced controller", Indonesian Journal of Electrical Engineering and Computer Science, vol. 17, no. 3, pp. 1626-1631, Mar. 2020.

[26] S.S. Reddy, Young Hawn Lho, "Optimum Location of Voltage Regulators in the Radial Distribution Systems", International Journal of Emerging Electric Power Systems, vol. 17, no. 3, pp. 351-361, Jun. 2016.

[27] K. Suresh, P. Anusha, Sk. Najma, B.I. Rajkumar, Ch.R. Reddy, B.P. Lakshmi, "A passive islanding detection method for hybrid distributed generation system under balanced islanding", Indonesian Journal of Electrical Engineering and Computer Science, vol. 14, no. 1, pp. 9-19, Apr. 2019.

[28] T. Sinha, P. Ray, S.S. Reddy, "Protection Coordination in Microgrid using Fault Current Limiters", Journal of Green Engineering, vol. 8, no. 2, pp. 125-150, 2018.

[29] S.S. Reddy, "Optimal reactive power sizing in a distributed network", International Journal of Engineering \& Technology, vol. 7, no. 4, pp. 3312-3316, 2018.

[30] S.C. Shekar, G.R. Kumar, S.V.N.L. Lalitha, "A transient current based micro-grid connected power system protection scheme using wavelet approach", International Journal of Electrical and Computer Engineering, vol. 9, no. 1, pp. 14-22, Feb. 2019.

[31] M.A. Abido, "Optimal power flow using particle swarm optimization", International Journal of Electrical Power \& Energy Systems, vol. 24, no. 7, pp. 563-571, Oct. 2002.

[32] Ch.R. Reddy, K.H. Reddy, "A Passive Islanding Detection Method for Neutral point clamped Multilevel Inverter based Distributed Generation using Rate of Change of Frequency Analysis", International Journal of Electrical and Computer Engineering, vol. 8, no. 4, pp. 1967-1976, Aug. 2018.

[33] S. Raza, H. Amjad, M. Umer, A. Khalid, "Analysis of power system parameters for islanding detection using wavelet transform", Indonesian Journal of Electrical Engineering and Computer Science, vol. 17, no. 3, pp. 1184-1193, Mar. 2020.

[34] P. Ray, B.K. Panigrahi, N. Senroy, "Hybrid methodology for fault distance estimation in series compensated transmission line," IET Generation, Transmission \& Distribution, vol. 7, no. 5, pp. 431-439, May 2013.

[35] D. Pal, B.K. Panigrahi, S. Kewat, "A Hybrid Method for Islanding Detection of Inverter Interfaced Distributed Generators Utilizing Superimposed Component of d-axis Voltage," IEEE Energy Conversion Congress and Exposition, Baltimore, MD, USA, 2019, pp. 1020-1025.

[36] H. R. Baghaee, D. Mlakić, S. Nikolovski, T. Dragičević, "Support Vector Machine-based Islanding and Grid Fault Detection in Active Distribution Networks," IEEE Journal of Emerging and Selected Topics in Power Electronics, 2019.

[37] S.S. Reddy, C.M. Jung, "Short-Term Load Forecasting Using Artificial Neural Networks and Wavelet Transform", International Journal of Applied Engineering Research, vol. 11, no. 19, pp. 9831-9836, Oct. 2016.

[38] R. Nale, M. Biswal, N. Kishor, "A Transient Component Based Approach for Islanding Detection in Distributed Generation," IEEE Transactions on Sustainable Energy, vol. 10, no. 3, pp. 1129-1138, July 2019. 